\title{
O ACESSO À JUSTIÇA COMO PARTE DE UMA AGENDA DE POLÍTICAS DO ESTADO SUJEITAS A CONTROLE PÚBLICO E SOCIAL NO BRASIL
}

\section{THE ACCESS TO JUSTICE AS PART OF THE STATE'S POLITICAL AGENDA SUBJECTED TO PUBLIC AND SOCIAL CONTROL IN \\ BRAZIL}

${ }^{1}$ Amanda Alves de Souza

\section{Resumo}

Este artigo objetiva discutir especificidades da implementação de políticas de democratização do acesso à justiça no Brasil, tendo como pano de fundo os paradigmas liberal e social de acesso e a construção do Estado de bem-estar social no contexto brasileiro. Além disso, procuraremos demonstrar que, como reflexo da problemática estruturação do Estado de bemestar no Brasil, o judiciário assume o papel de "engenheiro" social e político nas funções jurisdicional e administrativa da justiça. O judiciário e o ministério público possuem o monopólio da condução de políticas que objetivam a ampliação do acesso à justiça, o que constitui em obstáculo a um controle social das mesmas.

Palavras-chave: acesso à justiça; administração da justiça; judiciário; estado de bem-estar social - democracia

\begin{abstract}
This article aims to discuss specificities about the implementation of politics to democratize the access to justice in Brazil, having as background the liberal and social paradigms of acess and the construction of the welfare state in the brazilian context. Furthermore, we will try to demonstrate that, as a reflect of the problematic structure of the welfare state in Brazil, the judiciary assumes the role of a social and political "engineer" in its jurisdictional and administrative functions. The Judiciary and the Public Attorney's Office have the monopoly on politics to increase the democratic access to justice, which constitutes an obstacle to its social control.
\end{abstract}

Key words: access to justice; justice administration; judiciary; welfare state; democracy

\footnotetext{
${ }^{1}$ Doutoranda pelo Programa de Pós-Graduação em Sociologia e Direito da Universidade Federal Fluminese, UFF - RJ, (Brasil). E-mail : amandaalves.advs@gmail.com
} 


\section{INTRODUÇÃO}

O Brasil não seguiu o modelo ocidental de conquista de direitos. Esta clareza facilita compreender porque nossas relações de acesso à justiça, a direitos e práticas de cidadania no Brasil são tão diferentes da Europa e da América do Norte. Entre os obstáculos ao acesso efetivo a direitos está a ausência de um plano de inclusão de negros ou da maioria da sociedade na esfera da cidadania após o período de escravidão, a manutenção do latifúndio rural e da propriedade sem fim social em contexto urbano (CARVALHO, 2008, p.21). Mesmo o exercício de direitos essenciais à democracia como a soberania popular e o direito ao voto direto e regular ainda buscam maturidade desde a sua (re)conquista a partir de 1988 .

Desde 1988, pelo fato da Constituição trazer amplo rol de direitos civis e sociais, grande expectativa passa a ser depositada no sistema de justiça como catalizador de processos de transformação social (WERNECK VIANNA, 1999, p.25). No entanto, para isso, seria necessário que o acesso ao sistema de justiça fosse democrático (NUNES; TEIXEIRA, 2013, p.9). As dificuldades de acesso a direitos civis e sociais via sistema de justiça foi assunto explorado por Moreira (2013) no período de abertura democrática desde os anos 80 até 2010.

Historicamente a assunção de funções do Estado pelas oligarquias locais permitiu que as funções judiciárias se tornassem instrumento de poderes pessoais. A jurisdição privada local chegou até mesmo a fazer frente a jurisdição real portuguesa que, pelo seu custo, esteve fora do alcance daqueles que não dispunham de recursos para dela demandar (CARVALHO, 2008, p.22). Por outro lado, outros instrumentos de acesso à justiça tais como o acesso ao registro cartorário dependiam da anuência da Igreja Católica. Não se poderia, portanto, questionar os limites de um tratamento isonômico de todos perante a lei pela dificuldade de consolidação de um poder efetivamente público do qual emanaria o Estado.

\section{ACESSO À JUSTIÇA E ESTADO DE BEM-ESTAR SOCIAL NO BRASIL, ESTADOS UNIDOS E EUROPA}

Países como os Estados Unidos, França ou Alemanha vivenciaram demandas por acesso a direitos pela via judicial como consequência da crise do Estado de bem-estar social ou o pleito para que direitos fossem ampliados aos segmentos populares (CAPPELLETTI, 
1988, p.11). A expansão do Welfare State naqueles países foi real e sua crise levou intelectuais a entenderem que a via judicial seria um caminho para se tornar direitos efetivos especialmente aqueles que promoviam a inclusão cidadã de minorias étnicas e imigrantes (NUNES; TEIXEIRA, 2013, p.45).

A força de autoridades regionais foi construindo um modelo de Estado brasileiro marcado por um executivo autoritário, pela resistência ao controle social da agenda política de Estado e por um judiciário que conviveu tanto com ingerências de poderes privados regionalizados quanto com interferências do próprio executivo. O projeto de Welfare State ensaiado no Brasil por Vargas a partir 1934 foi, em realidade, um Welfare State inacabado tanto pela ausência de democracia, cuja expressão máxima está no controle da cidadania política e repressão ao movimento sindicalista, como pela dominação política não apenas do legislativo, mas também de todo aparato judiciário (WERNECK VIANNA, 1999, p.18). O controle político exercido pelo executivo sobre os outros poderes e ausência de democracia se faziam sentir, inclusive, na própria concepção de jurisdição presente na forma como a jurisprudência dos interesses foi incorporada ao pensamento doutrinário brasileiro. No CPC de 1939, elaborado com o auxílio de juristas como Francisco Campos, a jurisdição é concebida como o monopólio de manter a segurança jurídica como representação dos interesses sociais. Diferentemente de outros países em que o interesse social nem sempre se confundia com projetos de interesse da administração pública estatal, no Brasil a atuação dos juízes como agentes de efetivação de direitos sociais estava atrelada a um modelo de Welfare State baseado em interesses e ações de controle do executivo. Não havia, portanto, um ativismo proveniente de uma atuação mais ou menos autônoma do judiciário no sentido de efetivação de direitos (NUNES; TEIXEIRA, 2013, p. 50)

$\mathrm{Na}$ maior parte do século XX, como ocorreu em outros países da América Latina, o judiciário e, consequentemente o acesso a ele, não figurou como parte da agenda política do Estado de superação de uma cidadania excludente no Brasil (SANTOS, 2007, p. 11). O movimento social em sua maioria também não observava nos órgãos do judiciário instrumentos para reivindicação de demandas populares ou meios de controle jurídico de ações dos outros poderes. ${ }^{2}$ Muito embora a Lei 1.060/51 já instituísse um sistema de

\footnotetext{
${ }^{2}$ Durante a Ditadura Militar, cabe salientar que até 1978, quando foi revogado o AI-5 pelo Congresso Nacional, atos administrativos praticados de acordo com suas disposições eram excluídos de apreciação judicial. A Constituição de 1967, emendada em 1969 pela EC nº 1, dispunha em seu Art. 153, parágrafo 4º que "a lei não
} 
assistência judiciária gratuita desde 1951, somente no final dos anos de 1980, com a redemocratização, a administração da justiça passou a fazer parte de uma agenda política do Estado e pública dos movimentos sociais e com isso ganhou destaque a questão do acesso à justiça sobretudo formal no Brasil. ${ }^{3}$

A partir do momento em que o judiciário passou a confrontar outros poderes através do ativismo judicial, do controle da legalidade das ações do executivo e a politizar-se no sentido de interferir e regular o jogo real de forças políticas, inclusive aquelas que compõem o Parlamento, ele se impõe não apenas como poder dentro do Estado, mas também como parte de uma agenda pública até então dominada pelo executivo (SANTOS, 2007).

$\mathrm{O}$ ativismo do judiciário nesse sentido é decorrente em grande medida do que se convencionou chamar de "curto-circuito" histórico, momento de promulgação da carta constitucional de 1988 em que se estruturou um novo projeto de Estado e uma série de direitos civis, políticos e sociais passam a fazer parte de um sistema positivo de garantias sem, no entanto, virem acompanhados de políticas e ações estatais de efetividade no mesmo sentido e alcance. Por outro lado, desmantelado o Walfare State brasileiro protagonizado pelo executivo, pela devastação política privatizante e flexibilizante dos anos de 1980, o judiciário passou a ser uma nova arena pública onde se demandava, principalmente no plano das relações individuais, direitos civis e sociais (WERNECK VIANNA, 1999, p. 22). ${ }^{4}$

Essa nova arena publica judicial é externa ao circuito político clássico baseado na tríade sociedade-partidos políticos-representação democrática, circuito esse que no Brasil ainda não se consolidou plenamente mesmo após a promulgação da Constituição de 1988 (NUNES; TEIXEIRA, 2013, p. 76). A questão do acesso à justiça apesar de passar a figurar na agenda política do Estado ainda assim carece de maior controle social ou público. A nova

excluirá da apreciação do Poder Judiciário qualquer lesão a direito individual”, o que denota a ausência de previsão constitucional de uma dimensão coletiva de tutela de direitos.

\footnotetext{
${ }^{3}$ A existência de Defensorias Públicas nos Estados da federação passou a ser prevista com a promulgação da Constituição de 1988. A previsão constitucional de autonomia funcional e administrativa para as Defensorias só ocorreu, porém, em 2004 após a aprovação da Emenda Constitucional no 45. Atualmente o Supremo Tribunal Federal vem discutindo na ADI $5296 \mathrm{em}$ face da $\mathrm{EC} \mathrm{n}^{\circ}$ 74/2013 a possibilidade de autonomia funcional e administrativa da Defensoria Pública da União e do DF.

${ }^{4}$ Interessante a observação de Nunes (2013) sobre a atuação do judiciário num contexto de desestruturação de políticas estatais de efetivação de direitos sociais. Nesse contexto, o judiciário funciona como agente capaz de suprir a falta de políticas públicas e ao mesmo tempo estabilizar reações sociais.
} 
arena publica constituída não está, portanto, sujeita aos controles sociais clássicos das democracias representativas, ou seja, em última instancia à soberania popular, estando a questão do acesso à justiça de alguma maneira sob o monopólio do que pensam os juízes e instituições jurídicas clássicas sobre o tema.

Ao longo do processo de consolidação democrática, a constatação pela maioria da sociedade, com a denúncia de movimentos sociais, de que havia uma lacuna de políticas do Estado que garantissem a efetivação de direitos civis e sobretudo sociais, demandou do judiciário um papel de distribuição da justiça que muito provavelmente também o consolida numa agenda política. Houve, sobretudo nos anos de 1990, um aumento da litigância judicial (SANTOS, 2007). ${ }^{5}$ Com isso, nasce para o Estado e para a sociedade brasileira a seguinte questão: como lidar com tamanha quantidade de processos judiciais? $\mathrm{O}$ aumento da quantidade de processo amplia a efetivação de direitos? Que outros instrumentos de ampliação do acesso à justiça vêm sendo colocados pelo Estado e pelos movimentos sociais como necessários de serem construídos?

Essas são questões que ainda demandam pesquisas atualmente, mas o que se pode perceber é que o ativismo do judiciário, desde a (re)democratização, guarda íntima relação com o deslocamento de uma "cidadania insurgente" em vias de afirmação, cuja origem estava até então no associativismo comunitário e no novo sindicalismo urbano (HOLSTON, 2013, p. 62). O aumento da atuação do judiciário como suposto "guardião de princípios democráticos" e "engenheiro social" significou que a sociedade brasileira depositou em grande medida na figura dos juízes e, consequentemente, no acesso à justiça formal a superação de déficits históricos relacionados a possibilidade de exercício pleno da cidadania. Por outro lado, a insuficiência de uma agenda de políticas do Estado para efetivação de direitos recémconsagrados na constituição de 1988 aumentou vertiginosamente a crença no judiciário e, conseqüentemente, fez crescer a quantidade de processos judiciais. Quanto maior o aumento da crença na salvaguarda judicial como instrumento de aceleração do acesso e efetivação de direitos, maior a possibilidade não apenas de aumento do acervo processual, mas também de desestímulo a uma cidadania reivindicatória, inclusive, de mais controle social das ações do Estado e da própria administração do acesso à justiça.

\footnotetext{
${ }^{5}$ Santos assinala que a litigação está relacionada com culturas jurídicas e políticas, mas também com nível da efetividade da aplicação de direitos e com a existência de estruturas administrativas que sustentem essa aplicação.
} 
Paralelamente ao aumento da crença no ativismo judicial, modificações de natureza constitucional e legislativa contribuíram significativamente para que o judiciário e o acesso à justiça se consolidassem como parte de uma agenda pública e política de Estado. Entre essas modificações podemos citar como relevantes a ampliação do rol de legitimados para propor ações de controle da constitucionalidade, a criação do instituto do amicus curiae nas ações de controle concentrado, a criação das ações coletivas para defesa de direitos coletivos, difusos e individuais homogêneos bem como a concessão de autonomia ao ministério público para investigar a atuação dos poderes públicos nos mais variados setores, podendo tornar judiciais questões de improbidade/moralidade administrativa e corrupção em diversos níveis. A previsão constitucional de defensorias públicas autônomas dentro de um sistema de assistência judiciária gratuita também depositou mais expectativas nos setores populares com relação a atuação do judiciário para efetivação de direitos e persecução de justiça social. Além disso, houve um aumento substancial de faculdades de direito em todo território nacional e, consequentemente, uma expansão no quadro da advocacia disponível (PORTO, 2000).

Como podemos perceber, o aumento da crença de setores populares na atuação do judiciário como forma de ampliação do acesso a direitos civis e sociais, acompanhados da promulgação de uma nova carta constitucional e modificações legislativas no sistema processual se, por um lado, consolidaram uma agenda de políticas públicas de ampliação do acesso à justiça no Brasil, por outro lado, deslocaram as forças de uma "cidadania insurgente" para arena judicial, cidadania esta essencial, conforme verificaremos mais adiante, para o desenvolvimento de um controle social da administração da justiça e das políticas de acesso à justiça no Brasil.

O aparato judiciário tem dominado de maneira instrumental, ou seja, de acordo com interesses, linguagens e concepções de eficiência gerencial elaboradas por juízes, tanto as políticas no sentido de ampliação do acesso à justiça formal como aquelas que objetivam desenvolver mecanismos de resolução de conflito alternativos. (HABERMAS, 2012, p.186). Além disso, a ampliação do acesso à justiça formal em grande medida promovida por iniciativas do próprio judiciário muito provavelmente vem sendo desenvolvida, por isso mesmo, de maneira desarticulada com outras instituições essenciais tais como ministério público, defensorias públicas, escritórios de advocacia, cartórios notariais, associações civis sem fins lucrativos, faculdades de direito e núcleos de assessoria/advocacia popular. 


\section{REFLEXÕES SOBRE AS PECULIARIDADES DAS TENTATIVAS DE DESENVOLVIMENTO DAS CHAMADAS “ONDAS RENOVATÓRIAS" DE ACESSO À JUSTIÇA NO BRASIL}

Assim como o Brasil não seguiu um modelo ocidental de desenvolvimento da cidadania, não é possível afirmar, como vem fazendo algumas instituições como o Ministério Público, que as "ondas renovatórias" de acesso à justiça ocorreram no Brasil tal como o modelo sistematizado e proposto por Cappelletti muito embora tenha o autor influenciado na formação de juristas brasileiros no sentido de despertar preocupações acadêmicas com o instrumental jurídico-processual destinado a assegurar a efetividade de direitos positivados e o papel dos tribunais. ${ }^{6}$ Em primeiro lugar, cabe destacar que Cappelletti, ao elaborar projetos destinados a investigar e estudar a temática do acesso à justiça no mundo, a partir de 1970, não incluiu o Brasil no levantamento realizado entre países da América Latina, o que pode significar que as tentativas de implementação de "ondas renovatórias" no Brasil podem guardar especificidades que precisam ser observadas diante do modelo. Pesquisadores brasileiros compreendem que não há uma relação de identidade direta entre os estudos coordenados por Cappelletti e o advento do tema enquanto objeto de investigação no Brasil (NUNES; TEIXEIRA, 2013, p. 45). Cabe ainda destacar que a própria constituição do espaço público brasileiro possui características que necessitam ser levadas em consideração para compreensão da construção de nosso sistema de acesso à justiça.

Discutimos no tópico anterior que o período republicano brasileiro foi marcado pela ausência de democracia e controle da cidadania política, mesmo em momentos de avanços com relação a tutela e efetivação de direitos sociais. Por isso, as tentativas de definição e descrição do que seria o espaço público brasileiro envolvem a figura de um Estado que o controla e o instrumentaliza de acordo com "suas” regras (KANT DE LIMA, 2001, p. 14). No espaço público brasileiro, "tudo é possível”, ou seja, as esferas de exercício de liberdades individuais não aparecem com uma definição determinada de suas fronteiras.

\footnotetext{
${ }^{6}$ Essa constatação foi extraída de reflexões sobre o Manual de Negociação e Mediação para membros do Ministério Público elaborado, em 2014, por especialistas da Escola Nacional de Mediação e Conciliação.
} 
Além disso, esse exercício desigual de liberdades possui fluidez até que seja reprimido pela "autoridade", aquela que possui competência ou acesso privilegiado para interpretar o conteúdo e aplicação das regras do suposto sistema de direitos. O espaço público brasileiro possui como marca a sua instrumentalização histórica por agentes estatais dotados de "autoridade" ou por outros agentes regionais/locais por ele autorizados. De acordo com um modelo ocidental de construção da cidadania, superadas as noções estritamente liberais, do espaço público deveria emergir sentidos negociados de esferas de liberdades e regras compartilhadas de aquisição de direitos. O componente da legitimidade dentro do sistema de positivação gradativa de direitos e da construção da cidadania é, portanto, um componente problemático e que está no cerne da (in)definição do espaço público brasileiro. (HABERMAS, 1997, p.191)

Os debates jurídicos, acadêmicos e sociais que levaram Cappeletti a pesquisar problemas referentes ao acesso à justiça formal pressupunham a existência de um sistema de proteção jurídica conferida por meio da positivação de preceitos que gozavam de um grau mínimo de legitimidade. Cappelletti estava diante de uma maioria de países cuja esfera pública lhes conferia condições de criação de novos mecanismos de ampliação efetiva do acesso à justiça. Países como Alemanha, Itália, Estados Unidos e França, embora discutissem desigualdades sociais materiais que ofereciam obstáculos ao acesso à justiça, já vinham consolidando minimamente um sistema de mecanismos básicos de tutela e exercício efetivo de liberdades individuais e políticas, além de um sistema regular de eleições democráticas, que no Brasil ainda são objeto de desconfiança ou mesmo de controle de "autoridades" estatais ou regionais/locais autorizadas.

Realizadas as pesquisas sobre os obstáculos ao acesso a mecanismos de efetivação de direitos naqueles países, Cappelletti concluiu que as custas judiciais tanto com taxas cobradas pelos tribunais quanto com honorários advocatícios e sucumbenciais, somados à morosidade processual habitual, constituíam um dos principais problemas (CAPPELLETTI, 1988, p. 17). Além disso, o conhecimento acerca de direitos está intimamente relacionado com as condições sociais de vida e as possibilidades de acionar mecanismos estratégicos de efetivação dos mesmos. Quanto mais os segmentos populares desenvolverem conhecimentos jurídicos, maiores seriam as capacidades e aptidões para acessar mecanismos de defesa de direitos até então mantidos como privativos de outros segmentos sociais. 
Com isso, reconhece o autor que a chamada hipossuficiência ${ }^{7}$ da parte no litígio pode não ser apenas relacionada a condição financeira, mas técnico-jurídica e social, uma vez que interesses processuais envolvem conhecimentos técnicos, experiências sociais e possibilidades de conseguir projetar o desenrolar do próprio litígio. Outra conclusão levantada diz respeito a identificação de violações de direitos em massa ou de uma coletividade. O sistema processual clássico, baseado em parâmetros de um laissez faire jurídico, não possuía mecanismos de tutela e defesa de interesses de sujeitos coletivos ou de interesses difusos próprios de uma sociedade de consumo em ascensão. Assim, o ingresso de uma demanda judicial individual em um universo de lesão a um interesse que, em realidade, é coletivo apenas reforçaria o quadro de violações, visto que não provoca fissuras nos alicerces de atuação de grandes empresários ou mesmo do Estado.

As "ondas renovatórias" representaram então modelos paradigmáticos de soluções para cada um desses obstáculos de acesso à justiça identificados nos relatórios de pesquisa dos diferentes países mencionados. No Brasil, a "primeira onda", referente a criação de um sistema de assistência judiciária gratuita para as pessoas mais pobres $^{8}$, aparece nos manuais associada à edição da Lei 1.060/51 (Lei de Assistência Judiciária) e à previsão de criação de Defensorias Públicas nos Estados e da União a partir da Constituinte de 1988. ${ }^{9}$ Ocorre que a conquista de autonomia funcional e administrativa das Defensorias Estaduais, condição sine qua non para sua real estruturação, só veio a ocorrer aproximadamente e de fato vinte anos depois de promulgada a constituição.

\footnotetext{
${ }^{7} \mathrm{O}$ instituto jurídico da hipossuficiência, desenvolvido em grande medida pela doutrina consumerista, pressupõe que a desigualdade das partes em uma demanda processual deva ser levada em consideração não apenas na sua propositura ou no momento de análise do mérito, mas durante a avaliação pelo juízo das possibilidades de produção de provas ou outras questões preliminares ao mérito principalmente nas causas de natureza individual.

${ }^{8}$ Os conteúdos dos critérios objetivos para definição de "pobreza" variaram de país para país. O sistema francês, por exemplo, de assistência judiciária gratuita foi idealizado, desde os anos de 1970, para atender pessoas cujos rendimentos mensais poderíam chegar a até 2.950 francos, rendimento este considerado suficiente para suprir necessidades de uma família de até quatro pessoas. O sistema visa atender, portanto, pessoas com condições materiais acima dos níveis de pobreza extremada. No Brasil, a Defensoria Pública normalmente se utiliza da contagem de salários mínimos para definir a condição de "pobreza" dos assistidos, embora não esteja excluída a possibilidade de deferimento assistência judiciária a outros casos particulares que não representam a maioria dos casos atendidos.

${ }^{9}$ Em 1930, o patrocínio gratuito de causas de pessoas mais pobres ainda era assumido precipuamente pela Ordem dos Advogados do Brasil nos mais variados estados da federação. A Constituição de 1934, embora tenha positivado o direito de assistência judiciária entre o rol de direitos individuais, não previa um sistema nacional autônomo propriamente dito de assistência judiciária gratuita nos moldes em que é concebido atualmente.
} 
Pesquisas empíricas publicadas em 2014 demonstraram que apenas a partir do ano de 2000 foram criadas Defensorias Públicas em todos os estados da federação e que, apesar da conquista da autonomia, somente $42,31 \%$ das Defensorias Estaduais receberam repasse das cotas mensais do orçamento público dos estados destinados à instituição (AVRITZER; MARONA; GOMES, 2014, p. 83). Além disso, a análise dos mapas das Defensorias feita pelos pesquisadores revelou que as Defensorias não conseguem atender demandas de metade das comarcas de todo Brasil e as comarcas atendidas, em sua maioria por um sistema de acompanhamento não informatizado, não são aquelas com índice de desenvolvimento humano (IDH) mais baixo. Apesar dos problemas colocados, em relação a anos anteriores, o número de atendimentos realizados aumentou $50 \%$ e ações ajuizadas mais de $60 \%$, sendo $80 \%$ delas de natureza individual e da área cível.

Antes mesmo da consolidação dos mecanismos e instituições dessa "primeira onda renovatória", segundo a explicação de alguns manuais, o Brasil teria passado a "segunda onda renovatória" com a Lei 7.347/1985 (Lei de Ação Civil Pública) e com a Le 8.078/1990 (Código de Defesa do Consumidor). Assim, o Ministério Público, ao adquirir legitimação coletiva universal e o dever de propor ou intervir em toda e qualquer ação civil pública, ação esta que pode vir precedida de inquérito civil para apuração da materialidade dos fatos alegados, inauguraria a "segunda onda renovatória” de acesso à justiça no Brasil.

Assim como a previsão constitucional de Defensorias Públicas nos Estados não significou a consolidação de um sistema de assistência judiciária gratuita ou de elementos da "primeira onda renovatória", modificações legislativas e processuais, no sentido de criar instrumentos de efetivação e tutela de direitos coletivos ou difusos, não significam que a sua utilização tenha se tornado parte das rotinas de funcionamento do Ministério Público na mesma proporção em que emergem demandas por tutelas desses direitos. ${ }^{10}$ Ainda que não se possa de antemão concluir que, de fato, o Ministério Público tenha aumentado ou aprimorado sua atuação frente ao crescimento de tais demandas, muito provavelmente a sua legitimação consolidou certa crença social no judiciário como nova arena pública de defesa de interesses coletivos (WERNECK VIANNA, 1999, p.22). Como nos ensina Nunes (2013), essa espécie de judicialização do interesse público cataliza a formação de uma cidadania ativa que

\footnotetext{
${ }^{10}$ Não encontramos neste estudo dados empíricos acerca da frequência com que, ao longo dos últimos 20 anos, o Ministério Público passou a utilizar instrumentos de tutela e efetivação de direitos difusos.
} 
movimenta segmentos da sociedade em direção ao aprofundamento da democracia, cidadania esta que no Brasil aflora conjuntamente com a Lei de Ação Civil Pública. Ao mesmo tempo, tal judicialização insere na arena judicial pública linguagens e interesses políticos que jamais seriam objeto de discussão não fossem esses mecanismos de tutela coletiva.

O recurso a formas judiciárias simplificadas, a institutos e mecanismos que visam dar maior celeridade ao trâmite processual ou a formas não judiciárias de mediação como instrumento de desjudicialização da resolução de conflitos seriam os elementos principais da "terceira onda renovatória" que, no Brasil, aparece em geral associada a edição da Lei 9.099/95 (Juizados Especiais) ${ }^{11}$, à Lei 10.259/01 (Juizados Federais), à Lei 9.307/1996 (Lei de Arbitragem), à Lei 13.140/2015 (Nova Lei de Mediação) e as atuais reformas no código de processo civil que projetam a mediação como solução de descongestionamento do judiciário. $^{12}$

A implementação de juizados especiais, de inspiração nos Poor Man's Court norteamericano, ocorreu no Brasil sete anos após a promulgação da Constituição de 88 que, antes mesmo da edição da Lei 9.099/95, previa a criação dos mesmos. Como $80 \%$ dos casos de crimes de menor potencial ofensivo que chegavam até o juizado eram relativas a crimes praticados contra a mulher em âmbito doméstico, diante dos apelos do movimento feminista, em 2006, após a aprovação da Lei Maria da Penha, foram criados os Juizados de Violência Doméstica e Familiar contra a Mulher (RANGEL, 2013, p. 23). Parece-nos, diante de estudos empíricos publicados, que a criação destes últimos diferentemente dos primeiros sofreu uma interferência e controle social maior por parte dos movimentos sociais, especialmente do movimento feminista.

Em que pese tenham os juizados especiais se ramificado pelas estruturas judiciárias, em tese norteados por princípios redutores de complexidade processual tais como a oralidade, informalidade e economia processual, o aprimoramento de seus mecanismos de

\footnotetext{
11 A criação dos juizados especiais foi precedida da criação dos juizados de pequenas causas a partir da Lei $7.244 / 84$.

12 De acordo com os raciocínios elaborados em relação às chamadas "ondas renovatórias" a criação de institutos relevantes ao processo de ampliação do acesso à justiça, como é o caso da introdução antecipação dos efeitos da tutela jurisdicional ainda no processo civil de 1973 pela Lei 8.952/94 e Lei 9494/97, estaria inserida na "terceira onda renovatória". Porém, tal instituto é utilizado tanto em causas de alta como em causas de menor complexidade e não tornou necessariamente o processo de conhecimento ordinário ou recursal mais célere, muito embora possa produzir os efeitos de impedir o perecimento do direito ou da pretensão punitiva antes do trânsito em julgado da sentença.
} 
funcionamento ainda é regido e controlado por juristas, cuja formação e cultura reproduz uma tradição de civil law ou um habitus que não privilegia a negociação de sentidos de justiça pelas partes envolvidas no conflito ou um controle social do processo de resolução de conflitos baseado na legitimação das partes e na ampliação do acesso a direitos reconhecidos (KANT DE LIMA, 2009; BOURDIEU, 1989).

As partes envolvidas no conflito, por sua vez, também refletem essas tradições e reforçam o habitus do campo jurídico como nos demonstraram os estudos etnográficos realizadas nos juizados. Apesar da existência de conciliadores que não são advogados e da figura do conciliador ter sido criada para, em tese, cumprir papéis diferenciados de resolução de conflitos, o tratamento dado aos conciliadores como "doutores" ou "vossa excelência", tratamento esse conferido a figuras com poder institucional, ilustra peculiaridades das tentativas de implementação da chamada "terceira onda renovatória" de acesso à justiça em nosso contex to (RANGEL, 2013, p. 30).

Outro fato observado refere-se à importância conferida tanto ao domínio da linguagem técnico-jurídica para enfrentamento de intervenções elaboradas por advogados, já que as partes comparecem ao juizado patrocinadas por eles, como também ao "adequado" preenchimento da assentada ou ata da audiência. A partir dessas e de outras observações sobre o comportamento de conciliadores, Rangel (2013) coloca que o saber que orienta as práticas de conciliadores nos juizados especiais não é um saber prático, ou seja, um saber desenvolvido pelo aperfeiçoamento de práticas e soluções elaboradas pelos próprios conciliadores ao longo do contato com demandas reais. Aliás, outros acadêmicos advertem que o uso de formas alternativas de resolução de conflito no Brasil não tem sido levado a sério em face das inconsistências de formação dos que se propõem a realizá-los e da ausência de um pensamento que dimensione as múltiplas escolhas que as partes podem fazer durante o procedimento de negociação (NUNES; TEIXEIRA, 2013, p. 5). Por conta disso, a lógica de funcionamento e de resolução de conflitos desenvolvida pelos juizados pode ter se orientado por parâmetros normativos (dever ser), sociais e culturais que se diferenciam dos modelos de ampliação de acesso à justiça presentes na sistemática do modelo das “ondas renovatórias". ${ }^{13}$

\footnotetext{
${ }^{13}$ Sobre a lógica de funcionamento dos juizados especiais, vale ressaltar que tem reproduzido uma lógica gerencial de administração da justiça adotada pelos tribunais em que se assumem compromissos com produtividades numéricas e índices quantitativos produzidos por sistemas institucionalizados. (NUNES; TEIXEIRA, 2013, pg. 13)
} 
Além do conjunto de leis, transformações e simplificações processuais e de instituições jurídicas até aqui apresentados, cabe ainda discutir como as alterações constitucionais introduzidas pela Emenda Constitucional $n^{\circ} 45$ de 2004 representaram perspectivas de ampliação do acesso à justiça formal. De acordo com o quadro sistemático elaborado por Ribeiro (2008), são basicamente três os eixos de reforma do judiciário identificados na emenda: i) o eixo relativo ao tempo de duração processual; ii) o eixo relativo a complexidade dos procedimentos judiciais; iii) eixo relacionado a transparência da prestação jurisdicional. No primeiro eixo, a emenda positiva o princípio da razoável duração do processo e a proporcionalidade entre o número de juízes na unidade jurisdicional com as demandas judiciais. No segundo, a reforma constitucional apresenta como inovação a imediata distribuição do processo judicial, a necessidade de observância do princípio da economia processual mesmo nos procedimentos de alta complexidade, que demandam por exemplo pericias ou emissão de pareceres técnicos, além da instituição do funcionamento ininterrupto da justiça (plantão judiciário). ${ }^{14}$ Para o terceiro eixo, além da constante informatização e publicizaçao não apenas das etapas processuais, tivemos ainda a ampliação do acesso a informações referentes a administração da justiça com a criação do Conselho Nacional de Justiça - CNJ.

Antes da criação do CNJ, cabe ainda destacar a criação da Secretaria de Reforma do Judiciário, no ano de 2003, com os propósitos de democratização do acesso a justiça e modernização do poder judiciário (NUNES; TEIXEIRA, p. 71).

Diante das discussões até aqui desenvolvidas, podemos perceber que diferentemente do que apresentam alguns manuais elaborados por instituições como o Ministério Público, o modelo de soluções baseado nas "ondas renovatórias" não foi realizado no Brasil nos mesmos moldes das principais democracias ocidentais e que as ações e políticas públicas no sentido de ampliação do acesso à justiça não significaram, conforme verificaremos mais adiante, a passagem de um paradigma liberal a um paradigma social de acesso à justiça. Diferentemente do que ocorreu em países europeus continentais e nos Estados Unidos, o projeto Florença de Cappelletti demosntra que neles as "ondas renovatórias" acompanham um contexto de

\footnotetext{
${ }^{14}$ Antes das modificações trazidas nesse segundo eixo, Ribeiro (2008) destaca que antes da EC n. 45 um processo judicial poderia demorar até 4 anos para ser distribuído a uma vara especifica em São Paulo.
} 
ampliação do Welfare State e a necessidade de se tornarem efetivos direitos sociais e difusos positivos até então negligenciados pelo sistema de justiça.

No Brasil, ao longo do processo de (re)democratização inaugurado com a promulgação da Constituição de 1988, a positivação de um sistema amplo de direitos e garantias veio desacompanhada de políticas sociais no mesmo sentido e alcance. Paralelamente, o judiciário ganha certa independência e projeta-se, por motivos jurídicos, históricos e culturais, como "engenheiro social e político" constituindo em nova arena publica, desta vez deslocada do eixo clássico baseado sociedade-partidos-representação, na qual se deposita na instrumentalização judicial anseios sociais de superação de déficits históricos de ampliação efetiva da cidadania. Com o ativismo judicial, consolida-se na agenda política do Estado a questão do acesso à justiça em que juízes e instituições como o Ministério Publico aparecem mais uma vez como protagonistas na formulação de políticas e soluções para a administração da justiça, preservando uma cultura de monopólio do judiciário na administração de conflitos.

\section{A INFLUÊNCIA DE CONCEPÇÕES DE ACESSO A JUSTIÇA SEGUNDO O PARADIGMA LIBERAL E SOCIAL NO CONTEXTO BRASILEIRO}

Quando se discute acesso à justiça, estivemos classicamente diante de dois paradigmas: o paradigma liberal e o paradigma social. No paradigma liberal, a valorização do indivíduo e das relações privadas estão na base da idéia de contratualismo. O Estado se estrutura no ordenamento jurídico, entendido como sistema de regras positivas, e privilegia o exercício da soberania popular por meio da função legislativa, encontrando justificação material na ordem natural da economia. O Direito limita as possibilidades de intervenção do Estado na esfera privada e tem por objetivo estabilizar expectativas generalizadas de comportamento, alçando como valor jurídico a igualdade de todos perante a lei. Como observa Nunes (2013), o princípio de justiça está lastreado pelo direito dentro deste paradigma no respeito que ele garante à liberdade em âmbito privado, pois as leis de mercado, tidas como leis naturais, são capazes de regular por si a vida em sociedade, suprindo quase que naturalmente necessidades sociais. O liberalismo à brasileira não apenas exaltou essa 
função do mercado como equivocadamente a opôs às funções clássicas do Estado, dando-lhes uma conotação de ineficiência e colocando o público num lugar caótico ou de corrupção.

Segundo o paradigma liberal clássico, o legislador soberano deve cumprir a função de perquirir a justiça durante a produção da ordem jurídica, sendo o acesso à justiça parte de sua agenda política e normalmente associado a alterações processuais. Os obstáculos de acesso à justiça são tratados como problemas técnicos presentes no exercício do direito de ação (NUNES; TEIXEIRA, 2013). Como o direito de ação ou de acesso à justiça é normalmente concebido como direito natural, sendo anterior ao Estado, pressupõe-se que todos os indivíduos partem de uma mesma condição de exercício, sendo essas condições questões de natureza privada. (CAPPELLETTI, 1988, p. 9). Além disso, diante do primado do princípio da legalidade, como sinônimo da expressão do exercício da função legislativa alicerçada numa suposta vontade geral ou soberania popular, não é possível a elaboração de interpretações que extrapolem o direito estritamente alegado pelas partes ou a distribuição da justiça, não sendo o juiz um sujeito ativo nesse processo.

No paradigma social, a questão do acesso à justiça ganha contornos diferenciados. Sua constituição coincide com a ascensão do Welfare State após a segunda guerra e consolidação de democracias representativas na Europa Continental (WERNECK VIANNA et all., 1997, p.239). O paradigma se afirma a partir do momento em que direitos sociais são reivindicados como direitos políticos e que a noção de igualdade formal perante a lei, ou de igualdade natural entre indivíduos, sofre abalos sociais e políticos cedendo lugar a noção de igualdade substantiva a ser garantida pelo direito. Além disso, o reconhecimento de diferenças e desigualdades e a percepção da noção de hipossuficiência permearam a afirmação da igualdade material como valor nesse novo paradigma.

Se antes os obstáculos ao acesso à justiça estavam relacionados a problemas técnicos no exercício do direito de ação, além de outros de natureza processual, no paradigma social tais entraves são encontrados em necessidades de materialização de direitos que podem ser percebidos antes mesmo do exercício do direito de ação como é o caso da indisponibilidade de recursos financeiros para pagamento de custas e honorários advocatícios. Para suprir as necessidades de materialização de direitos que emergiam nesse contexto, o Estado extrapolou limites antes estruturados dentro do paradigma liberal e passou a uma atuação positiva, através de um sistema de garantias, para assegurar o gozo efetivo de direitos principalmente 
os de natureza econômico-social. Essa atuação positiva pôde ser sentida na mudança de postura dos juízes que transformaram a postura de juízes-observadores para juízesadministradores. Se antes as decisões em sua maioria limitavam-se a declarar o direito arguido pelas partes, dentro do paradigma social o esforço interpretativo dos juízes vai além do alegado, dando lugar ao ativismo judicial. Houve uma politização do discurso jurídico e uma maior observância de problemas de distribuição da justiça ou de questões de inclusão étnicas, culturais e sociais de fundo que reconhecidamente passaram a permear as decisões judiciais.

O Brasil vivenciou uma contradição entre esses dois paradigmas de acesso à justiça a partir da promulgação da Carta Constitucional de 1988. De acordo com Werneck Vianna (1997), a Constituição de 1988 foi elaborada sob a influência do paradigma social (Welfare State), mas foi sucedida por um contexto de esvaziamento do Estado ou da cultura de "estadania" ou "estatolatria" que marca em parte a sua formação. Houve mais precisamente um esvaziamento do executivo como figura indutora e protagonista de desenvolvimento econômico-social, típica do Welfare State brasileiro. Assumiram então esse papel o Legislativo e o Judiciário. Muitas das transformações legislativas em âmbito processual e judiciário, associadas, como vimos em tópico anterior, em geral a ocorrência de uma suposta "primeira e segunda onda renovatória" de acesso à justiça no Brasil, contribuíram para alçar o judiciário à condição de "engenheiro político e social".

Pesquisas empíricas elaboradas nos anos de 1990 refletem esse contexto. Quando perguntados sobre uma agenda de políticas que seriam prioritárias para o desenvolvimento do país bem como sobre as ações do estado frente à economia, descentralizar as atividades do Estado e desburocratizá-lo aparece para os magistrados brasileiros como segunda prioridade, sendo a primeira uma política de investimentos em educação, coincidindo com uma tendência desfavorável à intervenção do Estado em âmbito privado (WERNECK VIANNA, 1997, p. 245). Contraditoriamente às respostas sistematizadas com relação à atuação do Estado, $83 \%$ dos juízes reconhecem o seu papel ativo no processo judicial, negando a neutralidade institucional (WERNECK VIANNA, 1997, p. 258). Isto quer dizer que o judiciário atribui a si mesmo, como parte do mesmo Estado que condena, o papel ativo de promoção de garantias e direitos, ao mesmo tempo em que afirma fazê-lo como "fiel intérprete da lei". Caberia a ele e à expansão do acesso ao judiciário, os papéis de promoção do Estado de Direito sem, no 
entanto, compreender essa promoção como algo relacionado à própria consolidação da democracia e da cidadania. As marcas da tradição histórica de controle da cidadania política e social pelo executivo, ainda que tendo como pano de fundo o paradigma social do Welfare State, se fazem refletir nas percepções e compreensões que o judiciário tem de si mesmo frente à promoção da cidadania e do acesso a direitos. -

\section{Conclusão}

Neste trabalho, concluímos na primeira parte que os entraves a um acesso à justiça democrático e sujeito a controle público estão relacionados com a própria construção do Estado de bem-estar social no Brasil. Enquanto Estados Unidos, França ou Alemanha passaram por momento histórico de crítica ao paradigma liberal de acesso à justiça e vivenciaram a expansão do Estado de bem-estar social, desenvolvendo soluções no sentido de ampliar a efetivação de direitos aos segmentos populares, minorias étnicas e imigrantes pela via judicial, o Brasil inaugurou um projeto de Welfare State, cujas características principais são a ausência de democracia, controle da cidadania política e repressão ao movimento social especialmente o movimento sindical. Na maior parte do século $\mathrm{XX}$, como em outros países latino-americanos, o acesso à justiça sequer figurava como parte da agenda de políticas sociais do Estado. Mesmo após a edição da Lei 1.060/51, que instituiu um sistema de assistência judiciária gratuita, isentando pessoas consideradas hipossuficientes do pagamento de custas e honorários advocatícios no âmbito judicial, não houve, de fato, uma ampliação do acesso à justiça, pois não havia uma rede de instituições essenciais a essa expansão como as Defensorias Públicas estaduais. O mapa das defensorias públicas revelou que estas apenas foram estruturadas com relativo grau de autonomia institucional em todos os estados da federação apenas no ano 2000.

Após 1988, como a promulgação da constituição trouxe amplo rol de direitos, inaugurando um "choque" ou "curto-circuito" histórico de ampliação de direitos e houve, em paralelo, uma política de enxugamento da máquina administrativa, depositou-se no sistema de justiça expectativas de transformação política e social, o que transformou o judiciário em nova arena pública. Essa nova arena pública, no exercício de sua atividade jurisdicional, não estava sujeita aos controles sociais clássicos das democracias representativas. O papel que passa a cumprir o judiciário brasileiro como "engenheiro" político e social e indutor de um 
sistema de distribuição da justiça coloca a questão do acesso à justiça como parte de uma agenda de políticas do Estado no sentido de buscar suprir déficits históricos de cidadania.

O poder judiciário, ainda refletindo a figura de catalizador de transformações sociais próprio do contexto, mantém sob o monopólio de juízes e instituições jurídicas clássicas como o Ministério Público, mesmo no exercício de atividades administrativas, o papel de sugerir ou estruturar políticas e mecanismos de ampliação do acesso à justiça. Por conta disso, a implementação de políticas no sentido de promover instrumentos de desjudicialização e formas não judiciárias de resolução de conflitos, associadas normalmente a "terceira onda" cappellettiana, em realidade reforçam uma civil law tradition que não privilegia a oralidade e a informalidade sem as quais não pode haver uma real negociação de sentidos de justiça pelas partes envolvidas no conflito. Houve, inclusive, um tratamento instrumental de mecanismos alternativos de resolução de conflito por juristas e juízes em função de interesses gerenciais e do cumprimento de metas de administração de conflitos que não foram discutidas numa esfera pública mais ampliada.

Como podemos perceber, o Brasil não segue as tendências do modelo de Cappelletti de soluções para a problemática do enfrentamento de obstáculos ao acesso à justiça justamente porque o judiciário ainda monopoliza a administração da justiça e se auto reproduz como "engenheiro" social. Além disso, o paradigma social de acesso à justiça, próprio de um projeto de Welfare State, não foi de todo verificado no contexto brasileiro. Em realidade, o Brasil experimentou uma certa contradição entre os paradigmas liberal e social de acesso à justiça. Se por um lado a constituição de 1988 foi elaborada sob a influência de um paradigma social, por outro lado foi sucedida pelo esvaziamento da "estatolatria" que marca sua formação, o que fez a sociedade depositar na figura do judiciário anseios de transformação política e social sem, no entanto, atentar para o fato de que o acesso a esse novo "engenheiro" social ainda permanecia desigual.

Apesar de sentidos avanços no sistema de assistência judiciária gratuita com a estruturação das defensorias públicas nos estados, dos mecanismos processuais de defesa de interesses coletivos e difusos e da tentativa de desjudicialização com o desenvolvimento de soluções alternativas de resolução de conflitos, podemos perceber que o enfrentamento dos obstáculos de ampliação do acesso desigual à justiça está relacionado, em grande medida, ao monopólio de juízes e instituições jurídicas de políticas nesse sentido. Falar em acesso à 
justiça democrático ou democratização do acesso à justiça pressupõe em alguma medida um controle social e público de políticas de administração da justiça até então sugeridas muitas das vezes pelo judiciário e instituições jurídicas clássicas. 


\section{REFERÊNCIAS BIBLIOGRÁFICAS}

AVRITZER, Leonardo; MARONA, Marjorie; GOMES, Lilian. Cartografia da Justiça no Brasil - uma análise a partir de atores e territórios. São Paulo: Saraiva, 2014.

BOURDIEU, Pierre. O poder simbólico. Tradução de Fernando Tomaz. Rio de Janeiro: Difusão Editorial, 1989.

CAPPELlETTI, Mauro; GARTH, Bryant. Acesso à justiça. Porto Alegre: Sergio Antonio Fabris, 1988.

CARVALHO, José Murilo de. Cidadania no Brasil: o longo caminho. $10^{\text {a }}$ Edição. Rio de Janeiro: Civilização Brasileira, 2008.

HABERMAS, Jürgen. Direito e democracia: entre a facticidade e vaidade. Volume I. Tradução Flavio Beno Siebeneuchler. Rio de janeiro: Tempo Brasileiro, 1997.

HABERMAS, Jürgen. Teoria do agir comunicativo: racionalidade da ação e racionalização social. Vomulme I. Tradução Paulo Astor Soethe; revisão da tradução Flavio Beno Siebeneichler. São Paulo: Editora WMF Martins Fontes, 2012.

HOLSTON, James. Cidadania insurgente: disjunções da democracia e da modernidade no Brasil. Tradução Claudio Carina; revisão técnica Luisa Valentini. $1^{a}$ Edição. São Paulo: Companhia das Letras, 2013.

KANT DE LIMA, Roberto de. Adminsitração de conflitos, espaço público e cidadania uma perspectiva comparada. Porto Alegre: Revista de Ciências Sociais, Vol I, No 2, dezembro/2001. P. 11-16.

Manual de negociação e mediação para membros do Ministério Público. Brasília: Ministério da Justiça, 2014.

MOREIRA, Rafaela Selem; CITTADINO, Gisele. Acesso individual e coletivo de moradores de favelas à justiça. Revista Brasileira de Ciências Socias, Volume 28, nº 81, fevereiro/2013.

NUNES, Dierle; TEXEIRA, Ludmila. Acesso à justiça democrático. Brasília: Gazeta Jurídica, 2013.

RANGEL, Victor Cesar Torres de Melo. “Nem tudo é mediável” - a invisibilidade dos conflitos religiosos e as formas de administração de conflitos (mediação e conciliação) no Rio de Janeiro. Dissertação (Mestrado). Niterói: Programa de Pós-Graduação em Antropologia, Instituto de Ciências Humanas e Filosofia, Universidade Federal Fluminense, 2013.

RIBEIRO, Ludmila. Emenda Constitucional $n^{o} 45$ e a questão do acesso à justiça. São Paulo: Revista de Direito GV, Jul-Dez 2008. P. 465-492. 
WERNECK VIANNA, Luiz et all. A judicialização da política e das relações sociais no Brasil. Rio de Janeiro: Editora Revan, 1999.

WERNECK VIANNA, Luiz et all. Corpo e Alma da Magistratura Brasileira. $3^{\text {a }}$ Edição. Rio de Janeiro: Revan, 1997. 